\title{
Subacute arsenic neuropathy: clinical and electrophysiological observations
}

\author{
MARTIN J MURPHY, LYNN W LYON, JERRY W TAYLOR \\ From the Neurology Service, Iowa City VA Medical Center, the Neurology Department, University of Iowa \\ College of Medicine, and the College of Pharmacy, University of Iowa
}

SUMMARY Two patients with subacute arsenic neuropathy are described and the results of serial conduction velocity determinations from the very early stages of the illness to partial recovery are reported. Sensory and motor deficits were maximal within four weeks of the estimated time of exposure. Recovery was slow, with only partial improvement of the neurological deficits two years after onset of the illness. Progressive slowing of motor conduction velocity was observed in the first three months followed by a gradual increase in velocity thereafter. The possible mechanisms underlying the temporal profile of the electrophysiological changes are considered. The need for initiating chelation therapy before the development of the neuropathy is emphasised.

The most frequent neurological complication of inorganic arsenic intoxication is a distal symmetrical polyneuropathy that may appear subacutely within days of massive intoxication or may develop insidiously after chronic environmental or industrial exposure. ${ }^{1-5}$ Arsenic neuropathy is considered a distal axonopathy ${ }^{6}$ possibly related to the binding of arsenic to dihydrolipoate, a sulf hydryl component of the pyruvate dehydrogenase complex required in the oxidation of pyruvate..$^{7-9}$ Histological studies of peripheral nerve have, for the most part, demonstrated axonal degeneration with predominant involvement of large myelinated fibres. ${ }^{1} 1011$ Chhuttani and Chopra, ${ }^{12}$ however, suggested that segmental demyelination and axonal degeneration might be equally prominent pathological features of the neuropathy produced by arsenic, from their observation of demyelination and remyelination in teased fibre preparations.

We report here two patients who developed a severe subacute polyneuropathy following acute arsenic intoxication that provided us with the opportunity to perform serial electrophysiological studies during the acute and recovery phases of the illness. Both patients were treated with D-penicillamine but the course of the disease was not apparently modified.

Address for reprint requests: MJ Murphy, MD, Department of Neurology, University of Iowa Hospitals and Clinics, lowa City, IA 52242, USA.

Accepted 22 May 1981

\section{Case reports}

\section{Case 1}

A 52-year-old man was in good health until two weeks before admission when he developed malaise, fever, mild non-productive cough and occipital headaches. These symptoms resolved within one week and were followed by numbness and tingling sensation in the toes and fingers and weakness of the legs. The patient had used alcohol in excess for several years, but otherwise the past history was unremarkable. On examination he was thin and appeared ill. The blood pressure was $98 / 50 \mathrm{~mm}$ $\mathrm{Hg}$ and the pulse was 84 per minute and regular. $\mathrm{A}$ diffuse confluent maculopapular scaly rash was present over the trunk, shoulders and anterior aspect of the thighs. The liver edge was palpable $2 \mathrm{~cm}$ below the right costal margin. There was moderate weakness of distal muscles of both upper and lower extremities. Touch and pain sensation were impaired in a glove-stocking distribution and proprioception and pallaesthesia were absent in toes and ankles. Muscle stretch reflexes were normal in the arms, but were absent in the legs; the plantar responses were flexor. Gait was broad-based and ataxic, tandem walking could not be performed and Romberg sign was positive.

The following laboratory abnormalities were found: haemoglobin $11 \cdot 2 \mathrm{~g} / \mathrm{dl}$, WBC $1700 / \mathrm{mm}^{3}$ with $7 \%$ eosinophils, aspartate aminotransferase (SGOT) 375 IU/1 (normal 7-40 IU/l) and alkaline phosphatase $252 \mathrm{IU} / \mathrm{l}$ (30-150 IU/1). Hepatitis-associated antigen, antinuclear antibody titres, serum VDRL, viral studies and urinary porphobilinogen were negative. Vitamin B-12 and folate serum levels were normal. The cerebrospinal fluid was clear and contained one lymphocyte per $\mathrm{mm}^{3}, 4.5 \mathrm{mmol} / \mathrm{l}$ 
of glucose and $0.65 \mathrm{~g} / \mathrm{l}$ of protein (normal 0.35-0.95 $\mathrm{g} / \mathrm{l}$ ).

During the initial 10 days after admission there was clear-cut daily progression of the sensory and motor deficits and burning paraesthesias appeared. All deep tendon reflexes disappeared and the patient became confined to a wheelchair. At no time was respiratory function compromised and cranial nerve function was not affected. The skin rash cleared spontaneously in the course of a few days. The leucopenia and eosinophilia resolved within five days and soon afterwards liver serum enzymes returned to normal. A 24 hour urine for heavy metal analysis collected on admission, returned three weeks later, showing a urinary arsenic concentration of $1260 \mu \mathrm{g} / \mathrm{l}(31.5 \mu \mathrm{mol} / \mathrm{l})$ [normal $<100 \mu \mathrm{g} / 1 \quad(<2.5$ $\mu \mathrm{mol} / \mathrm{l})$, Bio Sciences Lab, Ca]. Lead and mercury were not detected. Arsenic content of nails and scalp hair determined three weeks after admission were 23 and $10 \mu \mathrm{g} / \mathrm{gram}(0.57$ and $0.25 \mu \mathrm{mol} / \mathrm{gram})$ respectively [normal $<1 \mu \mathrm{g} /$ gram $(<0.025 \mu \mathrm{mol} /$ gram $)$ Bio Sciences Lab Ca].

D-penicillamine therapy was initiated approximately one month after admission, but had to be discontinued 11 days later because of the development of a skin rash and gastrointestinal discomfort. Five days later it was reinstituted and again discontinued after 15 days because of the recurrence of epigastric discomfort and elevation of liver enzymes (fig 1). Palmo-plantar hyperkeratosis and Mees' lines were first noted 30 to 40 days after admission. One month later very slow improvement in motor and sensory function was apparent. Three months after admission the patient was discharged walking and was followed regularly as an outpatient while actively involved in a physical therapy programme. Throughout the period of follow-up slow progressive improvement was observed. The strength of proximal limb muscles was normal when last examined 28 months after the onset of his illness. Moderate atrophy and weakness of the intrinsic muscles of the hands and feet and the distal muscles of the legs persisted. Sensory loss, predominantly involving vibration and position sense was still present in the hands and

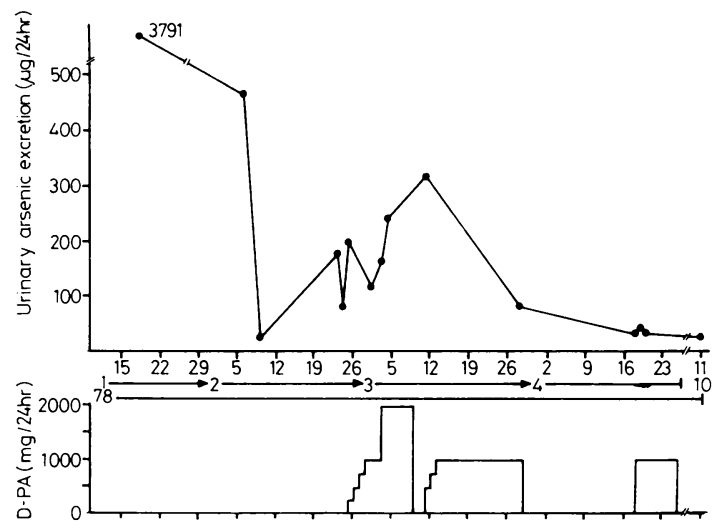

Fig 1 Case 1. Total daily urinary arsenic excretion and duration and daily dose of D-penicillamine therapy. distal to the knees. Muscle stretch reflexes in the arms returned, but remained absent in the legs. Although able to walk without assistance, his gait was unsteady with mild bilateral foot drop.

Case 2

A 59-year-old man was admitted to a local hospital after five days of persistent severe vomiting and watery diarrhoea. He was markedly dehydrated and the abdomen was distended and tender. Liver and spleen were not palpable. He was anaemic (haemoglobin $12.0 \mathrm{~g} / \mathrm{dl}$ and haematocrit $32 \%$ ) and leucopenic (WBC $330 / \mathrm{mm}^{3}$ with $6 \%$ eosinophils). The following laboratory values were abnormal: blood urea nitrogen $18.23 \mathrm{mmol} / 1$ (normal $1 \cdot 66-4 \cdot 33 \mathrm{mmol} / \mathrm{l}$ ), creatinine $194 \mu \mathrm{mol} / 1$ (normal $61 \cdot 8$ $123.7 \mu \mathrm{mol} / \mathrm{l}$ ), aspartate aminotransferase (SGOT) 93 IU/l (normal 7-40 IU/l), and alkaline phosphatase 101 IU/1 (normal 36-92 IU/1). Arterial blood gases and serum electrolytes were normal. A radiograph of the abdomen showed distended small bowel loops. A barium study showed failure of progression of the contrast material beyond the midportion of the ileum 11 hours after administration of the barium. Multiple diverticula of the sigmoid were demonstrated by barium enema. Intravenous pyelography was normal. Exploratory laparotomy performed the following day revealed a moderate amount of clear serous fluid in the peritoneal cavity and dilatation of both jejunum and ileum. No obstruction was found. The gall bladder was normal to palpation. During surgery $500 \mathrm{ml}$ of whole blood were transfused and $2 \mathrm{~g}$ of cephalotin sodium were given intravenously. Two days after surgery a papular erythematous rash was noted and the patient complained of weakness and dysaesthesias in the lower extremities. Eight days later the patient was transferred to our hospital. At this time the rash had disappeared, but the weakness and sensory disturbances were more pronounced. He was oriented in all spheres but was partially amnestic for the events of the previous two weeks. Marked symmetrical generalised weakness was present, more pronounced distally, such that upon maximal voluntary effort, he could barely overcome gravity. There was no atrophy. Marked sensory loss to all modalities was found in all four extremities, more severe distally. Proprioception and pallaesthesia were absent in the toes and ankles. Muscle stretch reflexes could not be elicited and no response was obtained on plantar stimulation.

A normochromic anaemia (haemoglobin $11.6 \mathrm{~g} / \mathrm{dl}$ ) and decreased total serum protein $(55 \mathrm{~g} / \mathrm{dl})$ and albumin $30.8 \mathrm{~g} / \mathrm{l})$. were found. Other laboratory studies were normal or negative, including serum glucose, antinuclear antibody titres, hepatitis-associated antigen, serum VDRL and urinary porphobilinogen. Cerebrospinal fluid was under normal pressure and contained no cells. CSF glucose was $3.5 \mathrm{mmol} / \mathrm{l}$ and protein was $0.58 \mathrm{~g} / \mathrm{l}$. A 24 hour urine specimen collected two days after transfer to our hospital had an arsenic concentration of $732 \mu \mathrm{g} / \mathrm{l}(18.3 \mu \mathrm{mol} / \mathrm{l})$. Lead and mercury were not detected. Scalp and pubic hair arsenic content three weeks after admission was $45.0 \mu \mathrm{g} / \mathrm{g}(1.12 \mu \mathrm{mol} / \mathrm{g})$ and $77 \mu \mathrm{g} / \mathrm{g}(1.92 \mu \mathrm{mol} / \mathrm{g})$ respectively.

In the first 10 days after the patient's transfer to our 
service the motor deficits progressed, rendering him tetraplegic and requiring total nursing care. Sensory deficits were profound with anaesthesia to all modalities in the lower extremities up to midcalf, such that the patient could not identify the location or posture of his feet when in bed. He also developed severe constant burning pain of all four limbs. When the results of the urinary arsenic analysis returned, the patient was started on D-penicillamine. Sequential total daily urinary arsenic excretion and length and dosage of D-penicillamine therapy are shown in fig 2 .

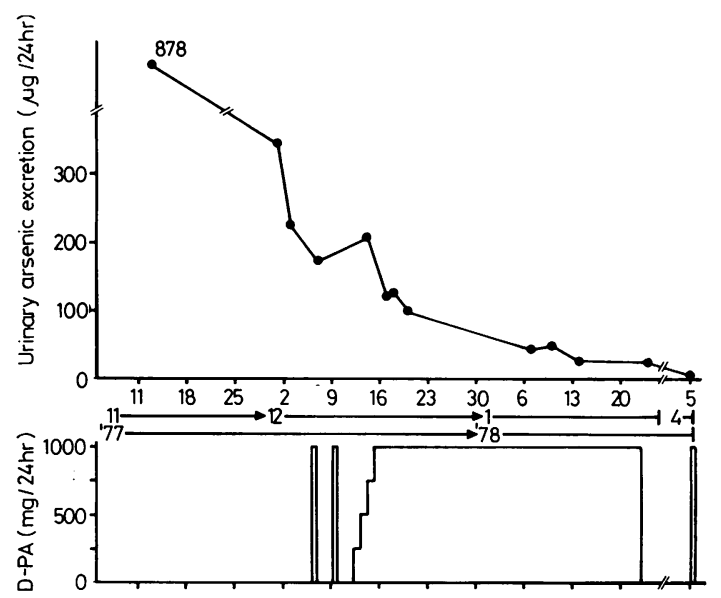

Fig 2 Case 2. Total daily urinary arsenic excretion and duration and daily dose of D-penicillamine therapy.

At the peak of his motor deficits approximately four weeks after the onset of his illness the patient was tetraplegic, only able to shrug his shoulders and initiate abduction of the arms. Trace movement was noted on attempted hip and knee flexion. Cranial nerve and respiratory muscles were not affected. Muscle stretch reflexes were absent. Prominent Mees' lines and hyperkeratosis of the palms and soles were noted one month after admission to our hospital. Two months later the patient had regained considerable strength in proximal muscles of both upper and lower extremities and was able to dorsiflex his wrists. He had developed marked atrophy of the intrinsic hand muscles, associated with bilateral clawhand deformity. Pallaesthesia and proprioception remained impaired below the hips, absent at the ankles and toes and decreased in the fingers. Light touch and pain were absent distal to the knees in both legs. Five months after admission the patient was able to feed himself and to sit up and move in a wheelchair. Four months later he was able to walk with the aid of a "walker". Twenty-four months after the onset of the illness, severe distal weakness of the legs with bilateral foot drop persisted. Moderate weakness of the hands and intrinsic hand muscle atrophy remained. A glovestocking sensory loss to all modalities persisted. Proprioception and pallaesthesia were the most affected.

\section{Electrophysiological studies}

Electromyography was performed with monopolar needle electrodes using a TECA (Model M) electromyographic apparatus. Motor nerve conduction velocity in the median, ulnar, peroneal and tibial nerves was measured using conventional techniques with surface stimulating and recording electrodes. ${ }^{13}$ Recording of sensory nerve action potentials from median, ulnar and sural nerves was attempted in both patients. ${ }^{1415}$ Room temperature was kept at $23^{\circ} \mathrm{C}$.

Electromyography showed a reduced interference pattern, fibrillations and positive sharp waves in the gastrocnemius and tibialis anterior of Case 1, and in the gastrocnemius, tibialis anterior, quadriceps, abductor pollicis brevis and extensor carpi ulnaris of Case 2 at the time of the first examination. Sensory nerve action potentials of the median, ulnar and sural nerves could not be recorded in either patient at the time of the first examination (three and four weeks after exposure respectively) and remained absent when the patients were last evaluated. Motor conduction velocities (table) were moderately reduced initially. Maximal slowing was found three months after exposure, followed by a gradual increase in the conduction velocity thereafter, returning to the normal ranges in the ulnar and median nerves of Case 116 and 28 months after intoxication respectively (fig 3 ). In both patients a selective involvement among the nerves tested was observed: both peroneal and tibial nerves were most severely affected and the ulnar to a lesser degree than the median nerve. The amplitude of the compound muscle action potentials became progressively reduced and could not be detected after stimulation of the tibial nerve in Case 1 and of the peroneal, tibial and median nerves in Case 2 at the time of most severe electrophysiological abnormalities. Serial determinations of the terminal latency in the median and ulnar nerves in Case 1 and of the ulnar nerve in Case 2 showed sequential changes in the conduction time similar to that of the forearm conduction velocity alterations.

\section{Discussion}

The historical and toxicological data suggest that both patients had a massive exposure to arsenic within a very restricted period of time. The flu-like syndrome observed in the first patient and the severe gastrointestinal disturbances in the second are well-known manifestations of acute arsenic intoxication, as are the fleeting skin rash and the transient haematological and hepatic alterations noted in these patients. Numbness and paraesthesias began 8 to 10 days after the estimated time of exposure with the development of a severe symmetrical sensori- 
Table Motor terminal latency and conduction velocity determinations

\begin{tabular}{|c|c|c|c|c|c|c|c|c|c|}
\hline $\begin{array}{l}\text { Case } 1 \\
\text { Time after exposure }\end{array}$ & $2 w k$ & $6 w k$ & $3 \mathrm{mth}$ & $6 m t h$ & $10 \mathrm{mth}$ & $16 \mathrm{mth}$ & $22 \mathrm{mth}$ & $28 m t h$ & Control (mean $\pm S D)$ \\
\hline \multicolumn{10}{|l|}{ Median nerve } \\
\hline Terminal latency (ms) & $4 \cdot 0$ & $4 \cdot 4$ & $6 \cdot 0$ & $5 \cdot 0$ & $5 \cdot 3$ & $4 \cdot 3$ & $3 \cdot 6$ & $4 \cdot 0$ & $3 \cdot 5 \pm 0.3$ \\
\hline Forearm velocity $(\mathrm{m} / \mathrm{s})$ & 40 & 37 & 32 & 35 & 41 & 42 & 44 & 52 & $56.6 \pm 4.3$ \\
\hline \multicolumn{10}{|l|}{ Ulnar nerve } \\
\hline Terminal latency (ms) & $2 \cdot 6$ & $2 \cdot 9$ & $2 \cdot 8$ & $3 \cdot 0$ & $3 \cdot 6$ & $3 \cdot 0$ & $2 \cdot 7$ & $2 \cdot 8$ & $2.5 \pm 0.4$ \\
\hline Forearm velocity $(\mathrm{m} / \mathrm{s})$ & 56 & 46 & 36 & 36 & 42 & 51 & 50 & 58 & $63 \cdot 4 \pm 7 \cdot 1$ \\
\hline Terminal latency (ms) & $4 \cdot 4$ & $4 \cdot 8$ & $7 \cdot 1$ & $8 \cdot 8$ & $6 \cdot 5$ & - & 一 & $6 \cdot 2$ & $4.5 \pm 0.9$ \\
\hline Velocity $(\mathrm{m} / \mathrm{s})$ & 33 & 33 & 22 & 24 & 31 & 30 & 29 & 30 & $49 \cdot 4 \pm 3 \cdot 8$ \\
\hline \multicolumn{10}{|l|}{ Tibial nerve } \\
\hline Terminal latency $(\mathrm{ms})$ & - & $5 \cdot 0$ & NR & NR & $5 \cdot 5$ & 一 & - & $5 \cdot 2$ & $4.4 \pm 0.6$ \\
\hline Velocity $(\mathrm{m} / \mathrm{s})$ & 30 & 29 & NR & NR & 27 & 30 & 29 & 31 & $44 \cdot 2 \pm 4 \cdot 1$ \\
\hline \multicolumn{10}{|l|}{ Case 2} \\
\hline $\begin{array}{l}\text { Time after exposure } \\
\text { Median nerve }\end{array}$ & $l \mathrm{mth}$ & $2 m t h$ & $3 m t h$ & $6 m t h$ & $9 m t h$ & $12 \mathrm{mth}$ & $24 m t h$ & & Control $($ mean $\pm S D)$ \\
\hline Forearm velocity $(\mathrm{m} / \mathrm{s})$ & 35 & & & & 23 & 33 & 29 & & $56.6 \pm 4.3$ \\
\hline \multicolumn{10}{|l|}{ Ulnar nerve } \\
\hline Terminal latency (ms) & $3 \cdot 0$ & $3 \cdot 2$ & $4 \cdot 1$ & $7 \cdot 2$ & $5 \cdot 7$ & $5 \cdot 0$ & $3 \cdot 2$ & & $2 \cdot 5 \pm 0.4$ \\
\hline Forearm velocity $(\mathrm{m} / \mathrm{s})$ & 39 & 31 & 26 & 28 & 38 & 38 & 43 & & $63 \cdot 4 \pm 7 \cdot 1$ \\
\hline \multicolumn{10}{|l|}{ Peroneal nerve } \\
\hline Terminal latency (ms) & $4 \cdot 9$ & NR & NR & NR & NR & NR & NR & & $4.5 \pm 0.9$ \\
\hline Velocity $(\mathrm{m} / \mathrm{s})$ & 24 & & & & & & & & $49.4 \pm 3.8$ \\
\hline \multicolumn{10}{|l|}{ Tibial nerve } \\
\hline $\begin{array}{l}\text { Terminal latency (ms) } \\
\text { Velocity }(\mathrm{m} / \mathrm{s})\end{array}$ & 24 & NR & NR & NR & NR & NR & NR & & $\begin{array}{r}4 \cdot 4 \pm 0 \cdot 6 \\
44 \cdot 2 \pm 4 \cdot 1\end{array}$ \\
\hline
\end{tabular}

NR $=$ no response. $\quad(-)=$ not available.

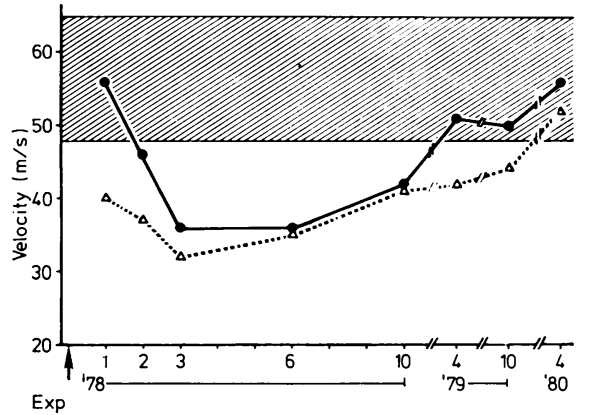

Fig 3 Forearm maximum motor conduction velocity in median $(\triangle)$ and ulnar $(\bigcirc)$ nerves of Case 1. Shaded area represents mean $+2 S D$.

motor neuropathy in the course of less than two weeks. Vibration and proprioception were the sensory modalities most severely affected and weakness was most marked distally in the legs. This clinical course corresponds to that described in previous reports and is characteristic of subacute arsenic neuropathy. 12410

Clinical recovery began within 6 to 8 weeks after exposure and gradual improvement continued for more than two years although prominent motor and sensory deficits were still present at the last examination. Such a slow and partial recovery has been recognised previously in patients with moderate to severe deficits at the peak of their illness. In the 40 patients reported by Chhuttani et $a l^{3}$ only six patients recovered completely within 40 days to 6 years, 24 recovered partially over a period of 5 months to 5 years, and two patients showed no improvement after a follow-up of 2 and 5 years, respectively. Similarly, the four patients reported by LeQuesne and McLeod, ${ }^{11}$ who had ingested a single dose of arsenic, had persistent symptoms and sensory and motor deficits 6 and 8 years after the intoxication.

Most previous electrophysiological studies in patients with arsenic neuropathy have reported single determinations of conduction velocities showing mild reduction in motor nerve conduction velocity and absence of sensory nerve action potentials. ${ }^{2} 10$ LeQuesne and McLeod ${ }^{11}$ found mild slowing of motor conduction velocity in their patients when first evaluated between five and ten weeks after exposure, with a gradual increase in velocity on repeat examinations performed 4 months and 8 years later. The serial determination of the conduction velocity performed in our patients provide the temporal profile of the electrophysiological changes from the very early stages of the disease to partial recovery. As has been the case in previous reports, sensory nerve action potentials were absent at the time of the first examination and remained so for the length of follow-up, reflecting severe involvement of sensory nerve fibres. 
The motor conduction velocity changes showed two distinct phases: in the first three months the velocity was progressively reduced, reaching its nadir some 90 days following exposure, followed by a gradual increase in velocity thereafter. The demonstration of active denervation by electromyography and the mild to moderate slowing in motor conduction velocity observed early in the course of the neuropathy correlates with the pathological evidence of axonal degeneration demonstrated in biopsy studies of sural nerve.1011 The marked reduction in velocity observed in the third month is unlikely, however, to be due to selective loss or failure of conduction of the larger fibres, factors which have been associated with the process of axonal degeneration. ${ }^{16-19}$

Two possible mechanisms may account for slowing of conduction of the magnitude observed. Conduction could be restricted to small diameter regenerating fibres, or alternatively, segmental degeneration may have developed as a secondary phenomenon, such as has been described in other human genetic and acquired neuropathies. ${ }^{19} 20$ The histological findings reported by Chhuttani and Chopra $^{12}$ would favour the second interpretation.

Chelation therapy in the treatment of arsenic neuropathy has been disappointing when started after the development of the neuropathy. ${ }^{1210}$ Although in both our patients D-penicillamine increased the urinary excretion of arsenic the course of the disease was not apparently modified. Because dimercaprol (BAL) and D-penicillamine have been effective in controlling the gastrointestinal and systemic effects of acute arsenic poisoning 82122 and in preventing the development of the neuropathy when given within hours of exposure, ${ }^{8}$ early confirmation of the diagnosis by qualitative arsenic determinations, such as that provided by the Gutzeit test, ${ }^{8}$ is imperative.

The skilful help of Mrs JM Hulme and Mr WD Jahnke is gratefully acknowledged.

\section{References}

${ }^{1}$ Heyman A, Pfeiffer Jr, JB, Willet RW, Taylor HM. Peripheral neuropathy caused by arsenical intoxication. $N$ Eng J Med 1956;254:401-9.

2 Jenkins RB. Inorganic arsenic and the nervous system. Brain 1966;89:479-98.

${ }^{3}$ Chhuttani PN, Chawla LS, Sharma TD. Arsenical neuropathy. Neurology (Minneap), 1967;17:269-74.

${ }^{4}$ Munasinghe DR, Rajasuriya K, Thenabadu PN. Polyneuropathy following acute arsenic poisoning. Ceylon Med J 1969;14:85-9.

${ }^{5}$ Feldman RG, Niles CA, Kelly-Hayes M, et al. Peripheral neuropathy in arsenic smelter workers. Neurology (Minneap) 1979;29:939-44.
'Sabri MI, Spencer PS. Toxic distal axonopathy: biochemical studies and hypohetical mechanisms. In: Spencer PS, Schaumburg HH, eds. Experimental and Clinical Neurotoxicology. Baltimore: Williams \& Wilkins Co, 1980:206-19.

7 Vallee BL, Ulmer DD, Wacker WEC. Arsenic Toxicology and Biochemistry. Arch Ind Health 1960;21: 132-51.

${ }^{8}$ Schoolmeester WL, White DR. Arsenic Poisoning. South Med J 1980;73:198-208.

${ }^{9}$ Politis MJ, Schaumburg HH, Spencer PS. Neurotoxicity of selected chemicals. In: Spencer PS, Schaumburg $\mathrm{HH}$, eds. Experimental and Clinical Neurotoxicology. Baltimore: Williams \& Wilkins Co, 1980:613-5.

${ }^{10}$ Goldstein NP, McCall JT, Dyck PJ. Metal neuropathy. In: Dyck PJ, Thomas PK, Lambert EH, eds. Peripheral Neuropathy. Philadelphia: WB Saunders Co, $1975: 1227-40$.

${ }^{11}$ LeQuesne PM, McLeod JG. Peripheral neuropathy following a single exposure to arsenic. $J$ Neurol $S c i$ 1977;32:437-51.

12 Chhuttani PN, Chopra JS. Arsenic poisoning. In: Vinken PJ, Bruyn GW, eds. Handbook of Clinical Neurology. Amsterdam: North Holland Publishing Co, 1979:199-216.

${ }^{13}$ Thomas PK, Sears TA, Gilliat RW. The Range of Conduction Velocity in Normal Motor Nerve Fibers to the Small Muscles of the Hand and Foot. J Neurol Neurosurg Psychiatry 1959;22:175-81.

14 Gilliat RW, Sears TA. Sensory Nerve Action Potentials in Patients with Peripheral Nerve Lesions. $J$ Neuro Neurosurg Psychiatry 1958;21:119-28.

${ }^{15}$ Burke D, Skuse NF, Lethlean AK. Sensory Conduction of the Sural Nerve in Polyneuropathy. $J$ Neurol Neurosurg Psychiatry 1974;37:647-52.

${ }^{16}$ Thomas PK. The Morphological Basis for Alterations in Nerve Conduction in Peripheral Neuropathy. Proc Roy Soc Med 1971 ;64:295-8.

${ }^{17}$ Gilliat RW. Recent Advances in the Pathophysiology of Nerve Conduction. In: Desmedt JE, ed. New Developments in EMG and Clinical Neurophysiology. Basel: Karger 1973;2:2-18.

${ }^{18}$ McLeod JG, Prineas JW, Walsch JC. The Relationship of Conduction Velocity to Pathology in Peripheral Nerves. In: Desmedt JE, ed. New Developments in EMG and Clinical Neurophysiology. Basel: Karger $1973 ; 2$ :248-58.

${ }^{19}$ Dyck PJ, Lais AC. Evidence for Segmental Demyelination Secondary to Axonal Degeneration in Friedreich's Ataxia. In: Kakulas, BK, ed. Clinical Studies in Myology. Amsterdam: Excerpta Medica, 1973.

${ }^{20}$ Dyck PJ, Johnson WJ, Lambert EH, O'Brien PC. Segmental demyelination secondary to axonal degeneration in uremic neuropathy. Mayo Clin Proc $1971 ; 46: 400-31$.

${ }^{21}$ Kuruvilla A, Bergeson PS, Done AK. Arsenic poisoning in childhood. Clinical Toxicology 1973;8(5): 535-40.

${ }^{22}$ Peterson RG, Rumack BH. D-Penicillamine therapy of acute arsenic poisoning. J Pediatr 1977;91:661-6. 